\title{
The Effect of Silica Loading on the Performance and Morphology of Polyimide-Silica Hybrid Membrane
}

\author{
N. S. A. Bakar ${ }^{1}$, S. A. Hashemifard ${ }^{2 *}$ \& A. Mustafa ${ }^{3}$ \\ ${ }^{1,2 \& 3}$ Advanced Membrane Technology Research Center (AMTEC), Faculty of Chemical and Natural Resources \\ Engineering, Universiti Teknologi Malaysia, 81310 UTM, Johor Bahru, Johor, Malaysia \\ ${ }^{2}$ Chemical Engineering Department, Engineering Faculty, Persian Gulf University, Bushehr 7516913817, Iran
}

\begin{abstract}
The performance of silica-polyimide hybrid membranes has been investigated for gas separation processes. The dope solution consisted of polyimide resin dissolved in NMP and silica sols at various weight percentages. The silica sols were prepared using a sol-gel process and the flat-sheet silica-polyimide hybrid membranes were cast using an immersion precipitation technique. The effects of silica sols loading on the gas transport properties of polyimide hybrid membranes and the correlation of morphology changes in the membrane structure and molecular orientation were studied. Polyimide hybrid membranes with silica sols loading ranging from 0 to $50 \mathrm{wt} \%$ were tested on gas permeation performance with single gas of $\mathrm{O}_{2}, \mathrm{~N}_{2}, \mathrm{CH}_{4}$ and $\mathrm{CO}_{2}$. The gas permeation results showed that the hybrid membranes with $20 \mathrm{wt} \%$ to $25 \mathrm{wt} \%$ silica loading exhibited higher selectivity than the pure polyimide membrane. Morphological properties and molecular orientations of the silica-polyimide hybrid membranes were also studied using SEM and FTIR, respectively. The SEM and FTIR results confirmed that the 20 and 25 wt $\%$ of silica loading was the ideal composition of polyimide-silica hybrid membrane for gas separation.
\end{abstract}

Keywords: Hybrid membrane, sol-gel, polyimide membrane, gas separation, silica loading

\subsection{INTRODUCTION}

Organic-inorganic hybrid and nano-composite membranes exhibit promising gas separation transport performance. By utilizing two materials with different gases fluxes, the separation properties of membrane can be improved. The hybrid materials have the potential to combine the desired properties of inorganic and organic system which can improve the mechanical and thermal properties of inorganic materials with the flexibility and ductility of organic polymers. These membranes are a new class of polymeric materials which possesses improved properties as compared to their neat materials. The typical hybrid

\footnotetext{
* Corresponding to: S. A. Hashemifard (email: salhashemifard@ yahoo.com)
}

membranes consist of porous inorganic particles dispersed into a polymer matrix. These membranes exhibit strong molecular sieving properties of a nano-filler such as zeolites, silica, alumina and molecular sieving carbons [1].

The most common methods to fabricate hybrid organic-inorganic membranes are melt blending and roller mixing. Solution blending is another simple method to fabricate polymer-inorganic nano-composite membranes. The polymer is primarily dissolved in solvent to form a solution before inorganic nanoparticles are added into the solution and dispersed by stirring. Nanocomposite membrane is formed upon removing of the solvent. The other method of adding fillers to the polymer matrix is in situ polymerization which nanoparticles are completely mixed with organic monomers followed by polymerization of the monomers. 
There are often some functional groups such as hydroxyl or carboxyl on the surface of inorganic particles, which can generate initiating radicals, cations or anions under high-energy radiation, plasma, UV or other sources of energy and subsequently initiate the polymerization of the monomers on the surface. The main disadvantages of incorporating fillers to polymers are agglomeration of particles and formation of nonselective voids at the interface of the particles and the polymer matrix [2]. Due to huge differences between polymer and inorganic materials in their properties and strong aggregation of nanofillers, polymer-inorganic nanocomposite membranes cannot be readily prepared by the common methods. The sol-gel method is the most widely used technique for the preparation of nanocomposite membranes. In this method, organic monomers, oligomers or polymers and inorganic nanoparticle precursors are mixed together in a solution whereas inorganic precursors hydrolyze and condense in the polymer matrix [2]. The advantage of this method is obvious; the reactions will be carried out at moderate conditions-usually. at room temperature and ambient pressure, and the concentrations of organic and inorganic components in the solution can be easily controlled. Additionally, the organic and inorganic ingredients are dispersed in the polymer matrix at the molecular or nanometer level, thus making the membranes much more homogeneous. The sol-gel formation of an inorganic particle within a polymer matrix depends on several parameters, such as temperature, solvent type, water-to-alkoxide ratio, type and concentration of catalyst, alkoxide precursor and $\mathrm{pH}[3]$.

The addition of inorganic nanofillers to a polymer membrane may affect its gas separation properties. Firstly, the interaction between polymer-chain segments and nanofillers can disrupt the polymer-chain packing and increase the voids (free volumes) between the polymer chains, thus promoting gas diffusion into the membrane. Secondly, the hydroxyl and other functional groups on the surface of the inorganic phase may interact with polar gases such as $\mathrm{CO}_{2}$ and $\mathrm{SO}_{2}$, improving the penetrant solubility in the nanocomposite membranes [2]. Finally, the presence of nanofillers particles brings about some sort of physical barriers in the polymer membrane which changes the gas permeation pathway to an indirect path, hence resulting in decreased polymer permeability [4]. The gas separation properties of numerous combinations of polymers and nanofillers have been explored so far using membranes such as the carbon molecular sieve-polysulfone membrane [5], the polyethersulfone (PES) -zeolite $4 \mathrm{~A}$ membrane [6], silica filler to the PEBAX (poly Iamide-6-bethylene oxide) membrane [7] and the hybrid membrane of polyvinylidene fluoride (PVDF)Silica [8]. Among nanocomposite membranes, polyimide-silica membrane has received most attention for the gas permeation studies [2]. Polyimide membrane is found to possess high gas permeability as well as high intrinsic selectivity in comparison to poly-carbonate, polysulfone and other materials [9]. Therefore, polyimide membranes have been widely used research to produce organic-inorganic hybrid membrane using alkoxide precursors to form microporous silica network system [10]. Moaddeb and Koros [11] studied the gas transport properties of thin polyimide in the presence of silica particles. The presence of silica is found to improve the gas separation properties of polyimide layers, particularly for $\mathrm{O}_{2}$ and $\mathrm{N}_{2}$ gases. Polyimide-silica composite membranes prepared by Joly et al., [12] introduced silica particle by sol-gel technique into synthesized polyimide film. The result showed higher permeability, selectivity and solubility coefficients than the pure polyimide. However, the imidization degree was around $75 \% \pm 7 \%$. Another study conducted by Cornelius et al. [10] was related to the effects of the alkoxysilanes loading and the morphology of the polyimide-silica composite membrane. The polyimide membranes were prepared from hexafluoroisopropylidene dipthalic anhydride (6FDA), hexafluoroisopropylidene dianiline (6FpDA) and diaminobenzoic acid (DABA) with the addition of various types of alkoxysilanes [10]. These membranes were annealed at $400^{\circ} \mathrm{C}$ and the gas permeation was increased up to $200-500 \%$ while the selectivity dropped slightly.

The objective of study is to prepare polyimidesilica hybrid membranes via a sol-gel process of tetraethylorthosilicate (TEOS) as this technique provides much simpler procedures without 
annealing or imidization process. TEOS were hydrolyzed and condensed to form a network of microporous silica sols [13].The silica sols were bonded with polyimide matrix in an attempt to improve the interaction between the polymer and the silica in order to enhance the separation performance [14]. The silica at various weight percentages were loaded into the polyimide (Matrimid( ${ }^{3}$ 128). The hybrid membrane was coated to heal the imperfections and to produce a practically useful membrane, since the coating is essential to seal the defects at the selective dense layer [15]. The fabricated polyimide-silica hybrid membrane with corresponding structural changes and permeation characteristics were investigated and thoroughly discussed.

\subsection{EXPERIMENTAL}

\subsection{Materials}

Figure 1 shows the chemical structure of polyimide Matrimid( 5128 used in this study. 1-methyl-2pyrrolidinone (NMP) as solvent for polyimide was

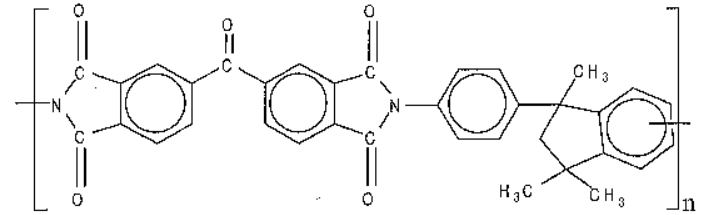

Figure 1 Chemical structure of polyimide Matrimid $\left({ }^{\circledR} 5128\right.$

supplied by Merck Co. and used as received. Ethanol and TEOS as alkoxide precursor with hydrochloric acid as the catalyst were used for solgel reaction.

\subsection{Silica Synthesis}

The silica sol was prepared using reaction of solgel that uses TEOS as an alkoxide precursor or alkoxysilane. Tetraethylorthosilicate (TEOS) is one of the most common silicon alkoxides which is commercially available. To perform the sol-gel process, stoichiometric amount of deionized water was added drop wise to a solution of ethanol-TEOS under vigorous stirring. The water and ethanol hydrolyzed and condensed the TEOS to form a

\section{Hydrolysis:}

$$
\mathrm{Si}(\mathrm{OR})_{4}+\mathrm{H}_{2} \mathrm{O} \stackrel{\mathrm{HCl}}{\longrightarrow}(\mathrm{RO})_{3} \mathrm{Si}-\mathrm{OH}+\mathrm{ROH} \quad \mathrm{R}: \mathrm{C}_{2} \mathrm{H}_{5^{--}}
$$

\section{Condensation:}

$$
\begin{aligned}
& >\mathrm{Si}--\mathrm{OH}+\mathrm{HO}--\mathrm{Si}<\underset{\mathrm{and} / \mathrm{or}}{\longrightarrow}>\mathrm{Si}-\mathrm{O}--\mathrm{Si}<+\mathrm{H}_{2} \mathrm{O} \\
& >\mathrm{Si}-\mathrm{OH}-\mathrm{OH}+\mathrm{HO}--\mathrm{Si}-\mathrm{Si}<+\mathrm{ROH}
\end{aligned}
$$

\section{Overall Reaction:}

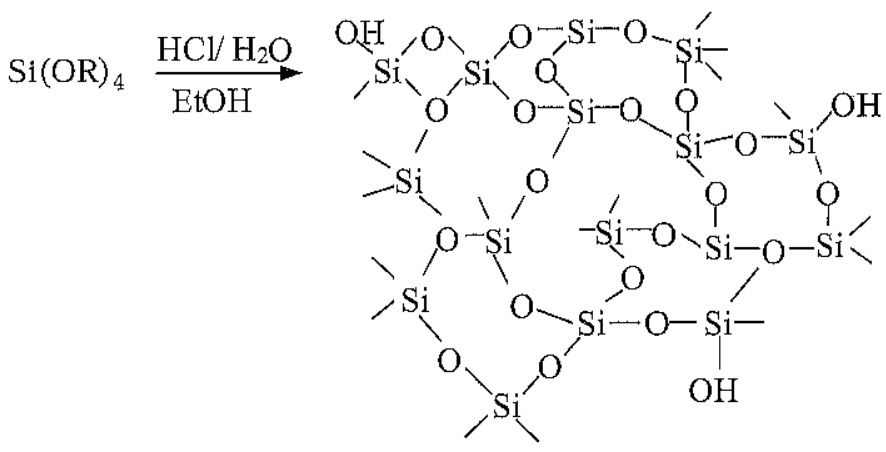

Figure 2 Sol-gel reaction of TEOS 
silica sol. The stoichiometric amounts used were $1.7 \mathrm{ml}$ of $37 \%$ hydrochloric acid $(\mathrm{HCl})$ and $12 \mathrm{ml}$ of deionzed water as well as $74 \mathrm{ml}$ TEOS in $2.13 \mathrm{ml}$ ethanol [16]. Then, the solution was fluxed at $80^{\circ} \mathrm{C}$ for an hour and stir with vigorous stirring, resulted a transparent silica sol,

The sol-gel reaction is generally divided into two steps: hydrolysis of TEOS to produce hydroxyl groups, followed by polycondensation of the hydroxyl groups and residual alkoxyl groups to form a three-dimensional network. The general scheme can be represented in Figure 2. From these three-dimensional networks, the microporous silica were produced and shown in SEM image (Figure 3).

Figure 3 shows the SEM image of microporous silica from sol-gel process. The addition of microporous silica network to the polyimide contributed to the increase of selectivity through molecular sieving mechanism, based on the differences in molecular size to achieve separation. Through the SEM image, the length of silica particle diameter could be measured directly from the photograph using the available scale on the photograph. The silica particles have the diameter of less than $50 \mathrm{~nm}$. But, naturally, the microporous silica produced from sol-gel reaction is predicted to have microspores with radius less than $1 \mathrm{~nm}$ [17]; however, the size of pores depends on the variables such as $\mathrm{pH}$, solvent, temperature, pressure, stoichiometry and evaporation rate.

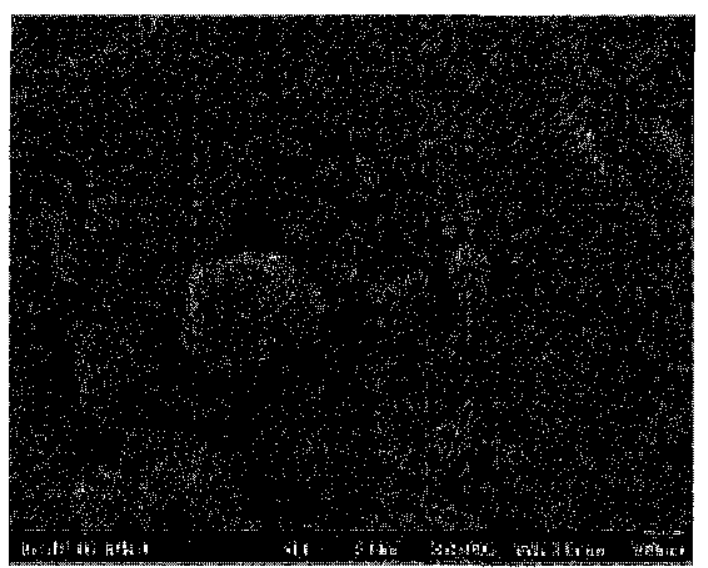

Figure 3 SEM image of microporous silica gel produced from sol-gel reactions

\subsection{Dope Solution and Membrane Fabrication}

In this study, the polyimide solution consists of 25 wt \% polyimide, $75 \mathrm{wt} \%$ NMP and $10-50 \mathrm{wt} \%$ silica sol on the total of solid. Several solutions were obtained with different in silica sol loading. The composition of the solutions showed in Table 1.

Table 1 Composition of polyimide-silica hybrid membranes solution

\begin{tabular}{cccc}
\hline $\begin{array}{c}\text { Membrane } \\
\text { samples }\end{array}$ & $\begin{array}{c}\text { Polyimide } \\
\text { (wt\%) }\end{array}$ & $\begin{array}{c}\text { NMP } \\
\text { (wt\%) }\end{array}$ & $\begin{array}{c}\text { Silica loading } \\
\text { (wt\%) } \\
\text { (composition } \\
\text { of total solid } \\
\text { weight) }\end{array}$ \\
\hline$M_{0}$ & 25 & 75 & 0 \\
$M_{10}$ & 25 & 75 & 10 \\
$M_{15}$ & 25 & 75 & 15 \\
$M_{20}$ & 25 & 75 & 20 \\
$M_{25}$ & 25 & 75 & 25 \\
$M_{30}$ & 25 & 75 & 30 \\
$M_{35}$ & 25 & 75 & 35 \\
$M_{40}$ & 25 & 75 & 40 \\
$M_{50}$ & 25 & 75 & 50 \\
\hline
\end{tabular}

Under the moderate stirring force, polyimide resins were added to NMP gradually until all of the polymers were dissolved in the solvent at the temperature of $50-60^{\circ} \mathrm{C}$. This process took about several hours to dissolve the entire polymer into the solvent. When all the polyimide has already dissolved in solvent, the silica sol added to this solution. The temperature continues at $50-60^{\circ} \mathrm{C}$ under vigorous stirring until all of the silica sol was dissolved into the membrane solution. This process took 5-7 hours to complete depend on the percentage of silica sol added.

This mixture was then cast through the immersion precipitation technique. The solution was cast onto a clear, flat and smooth glass plate. The glass plate with the membrane film was immersed into a water bath, where solvent exchange occurs and solidifies the membrane film to a complete membrane structure. To ensure all the solvent in the membrane structure was 
removed, membranes were immersed in an aqueous bath overnight. The membranes were finally air-dried at room temperature for 24 hours.

The hybrid polyimide-silica membranes were then coated with silicone rubber coating (Sylgard 184 Dow Corning). The membranes were submerged in the $3 \% \mathrm{w} / \mathrm{w}$ solution of silicone in n-hexane for a day and subsequently exposed to open air for a day or two to allow curing before the permeation testing.

\subsection{Characterizations}

The scanning electron microscope (SEM) was used to observe the morphology of membrane and distribution of the silica in the membrane. The samples were prepared by fracturing the hybrid membrane in liquid nitrogen. The membranes were then mounted on an aluminium disk and coated with platinum to prevent spatial resolution of the membrane area [18].

The hybrid polyimide-silica membranes containing various amounts of silica were analyzed by fourier transform infrared (FTIR) spectroscopy to determine the molecular orientation and functional groups in the membrane. The IR-spectra were obtained from a Spectra 5700 ATR-FTIR spectroscopy from Thermo Nicolet Corporation and Spectra Tech, USA. The IR-spectra showed the distribution of functional groups in each polyimide-silica membranes qualitatively.

\subsection{Gas Permeation Testing}

The gas permeability measurements of the hybrid membranes were carried out using a gas permeation cell; the membrane was placed on a sintered metal plate and pressurized at the feed side. The single-gas of oxygen $\left(\mathrm{O}_{2}\right)$, nitrogen $\left(\mathrm{N}_{2}\right)$, methane $\left(\mathrm{CH}_{4}\right)$ and carbon dioxide $\left(\mathrm{CO}_{2}\right)$ gases were tested. The effective membrane area was $13.5 \mathrm{~cm}^{2}$ and the permeation rates were measured at a constant of 4-bar pressure difference with soap bubble flow meter. The calculation of permeability in pressure normalized gas permeation flux or permeance for gas in GPU $\left(10^{-6} \mathrm{~cm}^{3}\right.$ (STP). $\left.\mathrm{cm}^{-2} \cdot \mathrm{s}^{-1} \cdot \mathrm{cmHg}^{-1}\right)$ unit, are shown as follows:

$$
\left(\frac{P}{l}\right)=\frac{Q}{A \Delta p}
$$

where $Q$ is the volumetric flow rate of the gas, $\Delta p$ is the pressure difference across membrane (cm $\mathrm{Hg}$ ), $A$ is the membrane affective surface area $\left(\mathrm{cm}^{2}\right)$ and $l$ is the membrane skin thickness $(\mathrm{cm})$.

The ideal separation factor $\alpha_{i / j}$ (the ratio of pair gas permeabilities) can be calculated by the following equation:

$$
\alpha_{i / j}=\frac{(P / l)_{i}}{(P / l)_{j}}
$$

where $\alpha_{i / j}$ is the ratio of permeability of gas $i$ and gas $j,(P / 1)_{i}$ is the permeability in pressure normalized flux for gas $i$ and $(P / 1)_{j}$ is the permeability in pressure normalized flux for gas $j$.

\subsection{RESULTS AND DISCUSSION}

\subsection{Characterization of Polyimide-silica Hybrid Membrane by FTIR}

Figures 4 and 5 demonstrate the IR-spectra of $\mathrm{M}_{0}, \mathrm{M}_{15}, \mathrm{M}_{20}, \mathrm{M}_{35}$ and $\mathrm{M}_{40}$ membrane samples. Figure 4 shows the spectra recorded in the region of $4000 \mathrm{~cm}^{-1}$ to $1600 \mathrm{~cm}^{-1}$ and Figure 5 shows spectra recorded in the region of $1800 \mathrm{~cm}^{-1}$ to $650 \mathrm{~cm}^{-1}$.

Figure 4 demonstrates the peak at $3439 \mathrm{~cm}^{-1}$ that was associated to vibration of hydrogen bonding. The increasing intensity of $\mathrm{O}-\mathrm{H}$ bond indicates that there was considerable amount of polyimide chains adhered on the silica where the intensity of the peak was higher at membrane $M_{15}$, $\mathrm{M}_{20}$ and $\mathrm{M}_{35}$ than other membrane samples. The hydrolysis reaction provides reactive silanol groups whereas condensation leads to the formation of bridging oxygen [19]. The silica produced by the sol-gel process was in a form of microporous silica network and was able to bond with the polyimide domain when they were mixed together.

On the other hand, the adsorption peak at $2954.4 \mathrm{~cm}^{-1}$ was related to aliphatic $\mathrm{C}-\mathrm{H}\left(\mathrm{CH}_{3}\right.$ and $\mathrm{CH}_{2}$ ) molecule structure. The peak was corresponded to symmetric stretch of aliphatic $\mathrm{C}-\mathrm{H}$ structure where the intensity of the peak for $\mathrm{M}_{0}$ membrane was lower than $\mathrm{M}_{15}, \mathrm{M}_{20}, \mathrm{M}_{35}$ and $\mathrm{M}_{40}$ membranes. These indicate that the hybrid 


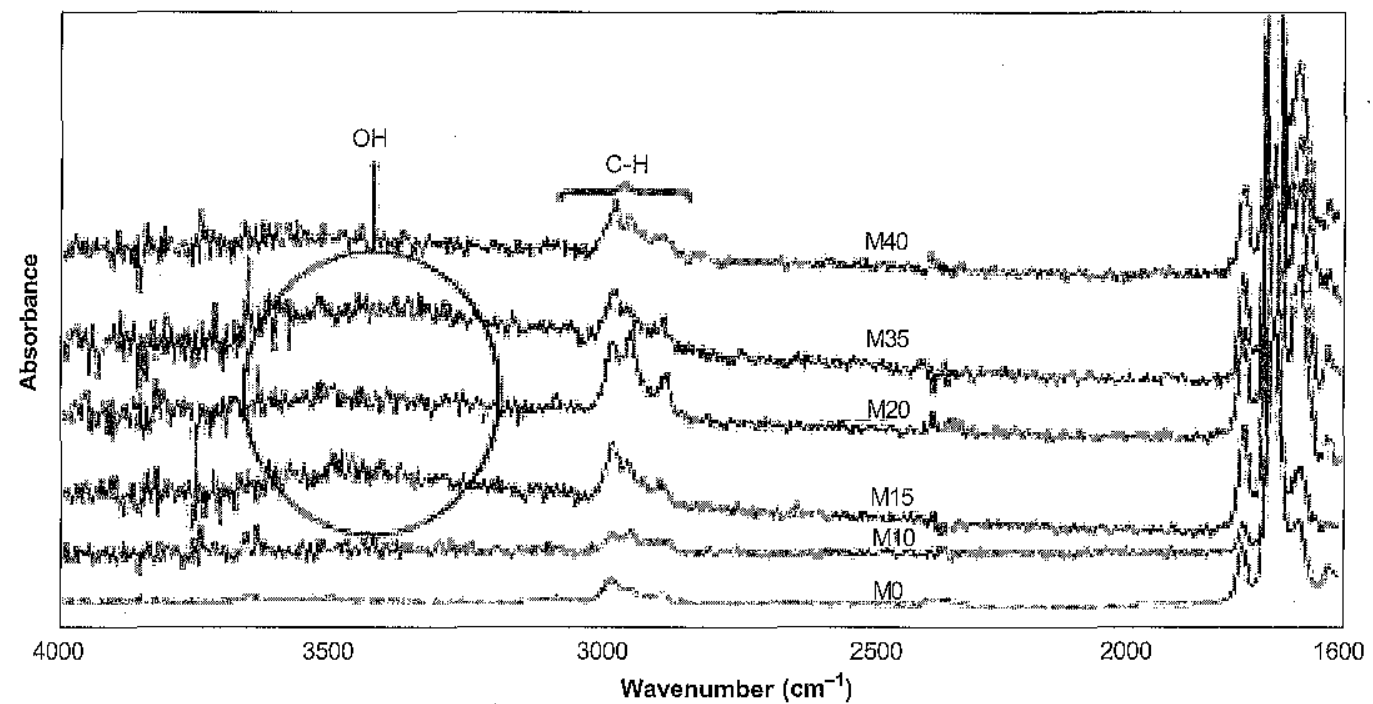

Figure 4 FTIR spectras in the region of $4000-1600 \mathrm{~cm}^{-1}$ for $M_{0}, M_{15}, M_{20}, M_{35}$ and $M_{40}$ membrane samples

membranes $\left(\mathrm{M}_{15}, \mathrm{M}_{20}, \mathrm{M}_{35}\right.$ and $\left.\mathrm{M}_{40}\right)$ have more aliphatic C-H structure than the pure polyimide $\left(\mathrm{M}_{0}\right)$.

Figure 5 shows the spectra of polyimide-silica hybrid membranes in the regions of 650 to 1800 $\mathrm{cm}^{-1}$. The peaks are interpreting some functional group from the FTIR spectra in the hybrid membrane samples such as carbonyl group, imides group and other. Table 2 summarizes the absorption peak of polyimide-silica membrane for specific functional groups.

It was expected that the silica from sol-gel reaction, the hybrid membrane sample should portray by $\mathrm{Si}-\mathrm{O}$ characteristic. However, the

Table 2 Infrared absorptions of polyimide-silica hybrid membranes

\begin{tabular}{ll}
\hline Wavelength $\left(\mathrm{cm}^{-1}\right)$ & Functional groups \\
\hline 1720.3 & $\begin{array}{l}\text { C=O symmetric stretch } \\
\text { (carbonyl group) } \\
\text { C-N-C (imide group) } \\
\text { primary }\end{array}$ \\
1207.8 & $\begin{array}{l}\text { C-N-C (imide group) } \\
\text { secondary }\end{array}$ \\
1672.2 & $\begin{array}{l}\text { Stretch band amide group } \\
\text { C }=\text { C of benzene rings in } \\
\text { polyimide }\end{array}$ \\
\hline
\end{tabular}

characteristic peak of Si-O stretching vibrations was not obvious; the trace was found for the band of $\mathrm{Si}-\mathrm{O}$ bending vibration at $780-770 \mathrm{~cm}^{-1}$. Although the adsorption was weak, the band showed an increase in adsorption intensity in $\mathrm{M}_{20}, \mathrm{M}_{35}, \mathrm{M}_{40}, \mathrm{M}_{15}$ and $\mathrm{M}_{10}$ which confirmed the existence of silica in the polyimide matrix. The $M_{20}, M_{35}$ and $M_{40}$ samples show the existence of $\mathrm{Si}-\mathrm{OH}$ bond at $945 \mathrm{~cm}^{-1}$. The Si-OH bond in $\mathrm{M}_{20}$, $\mathrm{M}_{35}$ and $\mathrm{M}_{40}$ samples were possible associated with the inter-crossing between polyimide network and silica. The excellent bonding between silica and polyimide network in hybrid membrane will be further proved by SEM images.

\subsection{Morphological Studies of Silica and Polyimide-silica Membrane}

As shown in Figure 6(a), the cross section view of polyimide-silica membrane $\mathrm{M}_{20}$ membrane. The membrane shows the asymmetric structures with finger-like pore-and dense top layer. The membrane with this structure can have a good gas separation. According to Baker (2000), asymmetric structures of the membrane with dense top layer promoted high separation ability. It appears that silica dispersion was not ideally occurred. Some silica agglomerated and scatter among the polymer matrix. The bonding between silica and polyimide 


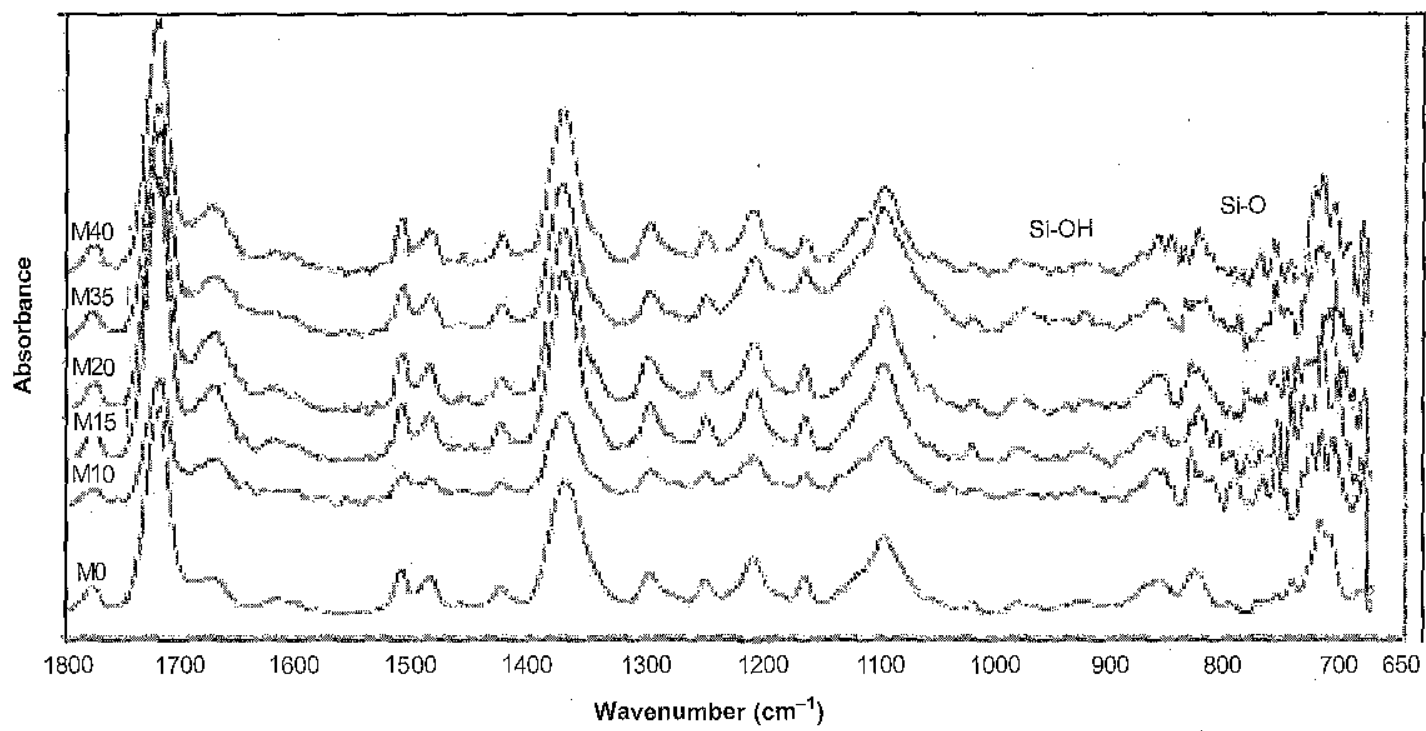

Figure 5 FTIR spectra in the region of $1800-650 \mathrm{~cm}^{-1}$ for $\mathrm{M}_{0}, \mathrm{M}_{10}, \mathrm{M}_{15}, \mathrm{M}_{20}, \mathrm{M}_{35}$ and $\mathrm{M}_{40}$ membrane samples

are rather strong in $\mathrm{M}_{20}$ membrane as was proved in FTIR result in Figure 5.

Through observation of Figure $6(b)$, the dense top layer of $\mathrm{M}_{20}$ membrane shows a smooth surface and no pin holes. It can be seen that in Figure 6(b) that silica particles were well embedded in the dense layer. Additionally, the rupture of surface active layers of the membrane was significantly suppressed due to better adherence of silica sol particles with the polymer matrix. The good adhesion of microporous silica to the polymer matrix was due to the formation of silica-polyimide bond. The FTIR analysis also reported that there's a good bonding between silica and polyimide for

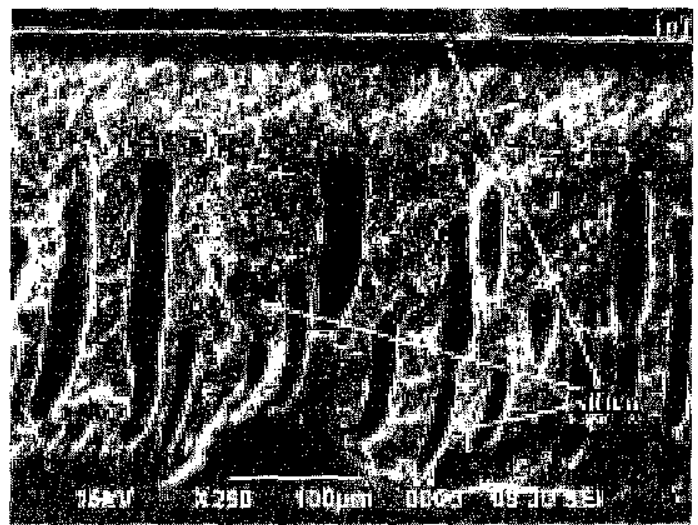

Figure 6 SEM images of $M_{20}$ hybrid membrane (a) cross-section ( $\left.\times 850\right)$ (b) surface layer $(\times 1000)$

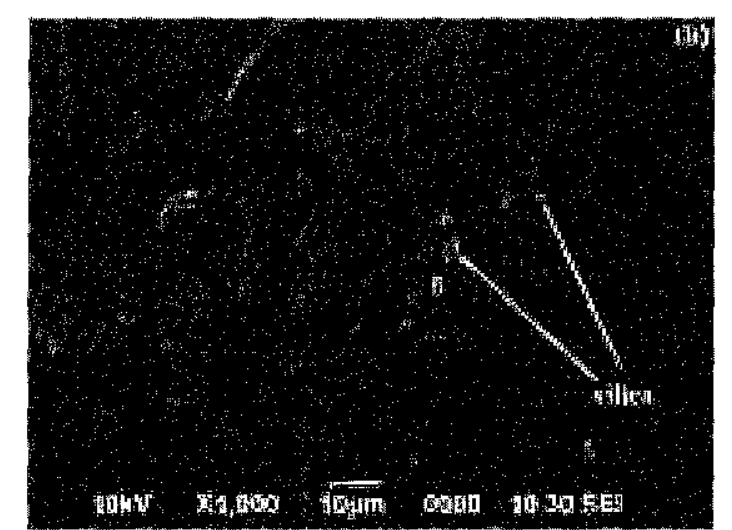

$\mathrm{M}_{20}$ membrane sample. Moreover, the smooth surface of hybrid membrane also indicates that silica sol particles were successfully bonded to the polyimide matrix. The same smooth surface structure of PI/PES-zeolite membrane from the work of Kusworo et al. (2008) also indicates that the zeolite particle adheres well to the polymer matrix [14].

Figure 7 shows the SEM images of $\mathrm{M}_{15}, \mathrm{M}_{35}$ and $\mathrm{M}_{50}$ membrane surface layer. From the image of $M_{15}$ membrane, it shows that silica did not intrude into the pores of the support layer and agglomeration of silica particles on the surface. This is mainly due to the effect of poor polymer 
contact to the silica. Although no obvious voids were seen from Figure 7(a), the nature of organicinorganic materials itself were realized to demonstrate organic-inorganic interfaces that will affect the performance of the membrane [20].

On the other hand, with more than $30 \mathrm{wt} \%$ silica loading, the polymer and silica interface become worse. Figure 7(b) shows the surface of membrane with $35 \mathrm{wt} \%$ of silica $\left(\mathrm{M}_{35}\right)$. The silica particles agglomerate on the surface of $\mathrm{M}_{35}$ membrane and appear to have wider organic-inorganic interfaces that are called voids. But still, there are some silica particles adhere to the surface and at a smaller size than that at the $\mathrm{M}_{15}$ membrane surface. This region shows a finer bonding between silica and polyimide as proved in FTIR result showing the present of $\mathrm{Si}$-OH bond in $\mathrm{M}_{35}$ membrane (Figure $5)$.

SEM image of $\mathrm{M}_{50}$ membrane, exhibit the clear surface of membrane layer with almost no silica particle at all. This possibly due to the high amount of silica loading that cannot be contained by the polymer matrix. Once the amount of silica sol reached 40 to $50 \mathrm{wt} \%$ loading to the polyimide matrix, the difficulties increased for silica to bond with polyimide matrix. The silica particles tend to bond together rather than to bond with the polyimide. These can cause the lost of silica during the fabrication of hybrid membrane thus leaving only small amount of silica in the polyimide matrix. Comparing $40 \mathrm{wt} \%$ of silica loading to $50 \mathrm{wt} \%$ of silica loading, $\mathrm{M}_{40}$ membrane are better than $\mathrm{M}_{50}$ membrane at compatibility between organic and inorganic materials. This proved with the existence of $\mathrm{Si}-\mathrm{OH}$ bond in $\mathrm{M}_{40}$ membrane through FTIR analysis result in Figure 5. Even so, good compatibility between organic and inorganic materials does not indicate that the membranes have good separation properties. Further verification of the membrane separation performance can be concluded in gas permeation testing results.

\subsection{The Permeability Study of Polyimide- silica Membrane}

In this study, permeation of $\mathrm{N}_{2}, \mathrm{O}_{2}, \mathrm{CH}_{4}$ and $\mathrm{CO}_{2}$ gases through polyimide-silica hybrid membranes
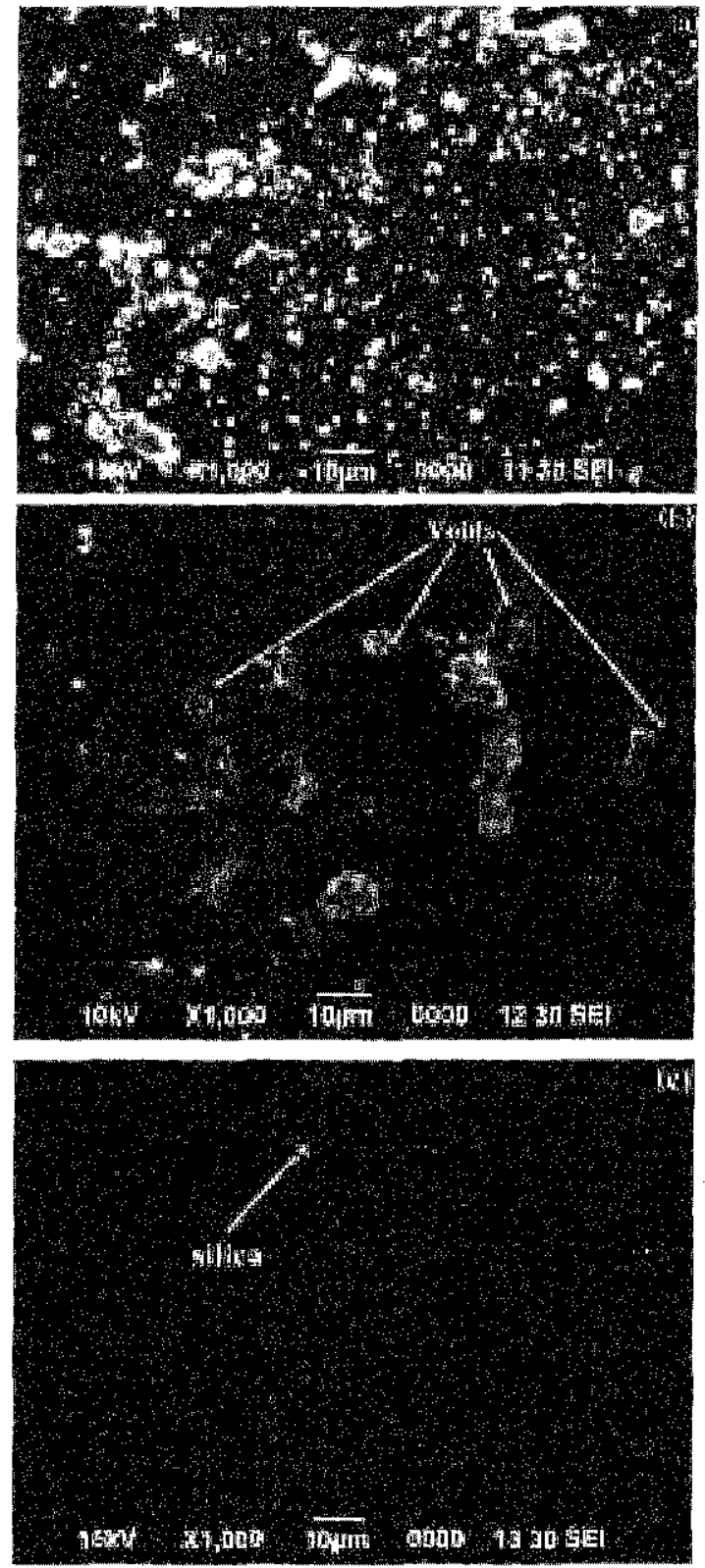

Figure 7 SEM image of hybrid polyimide-silica membrane surface layer: (a) $\mathrm{M}_{15}$ (b) $\mathrm{M}_{35}$ and (c) $\mathrm{M}_{50}$

was carried out at room temperature and 4 bar pressure. Figure 8 shows the permeability of $\mathrm{CO}_{2}, \mathrm{~N}_{2}, \mathrm{O}_{2}$ and $\mathrm{CH}_{4}$ gases at 4 bar pressure as a function of various silica loadings.

Figure 8 shows the permeability of $\mathrm{CO}_{2}, \mathrm{~N}_{2}, \mathrm{O}_{2}$ and $\mathrm{CH}_{4}$ gases as a function of various silica 


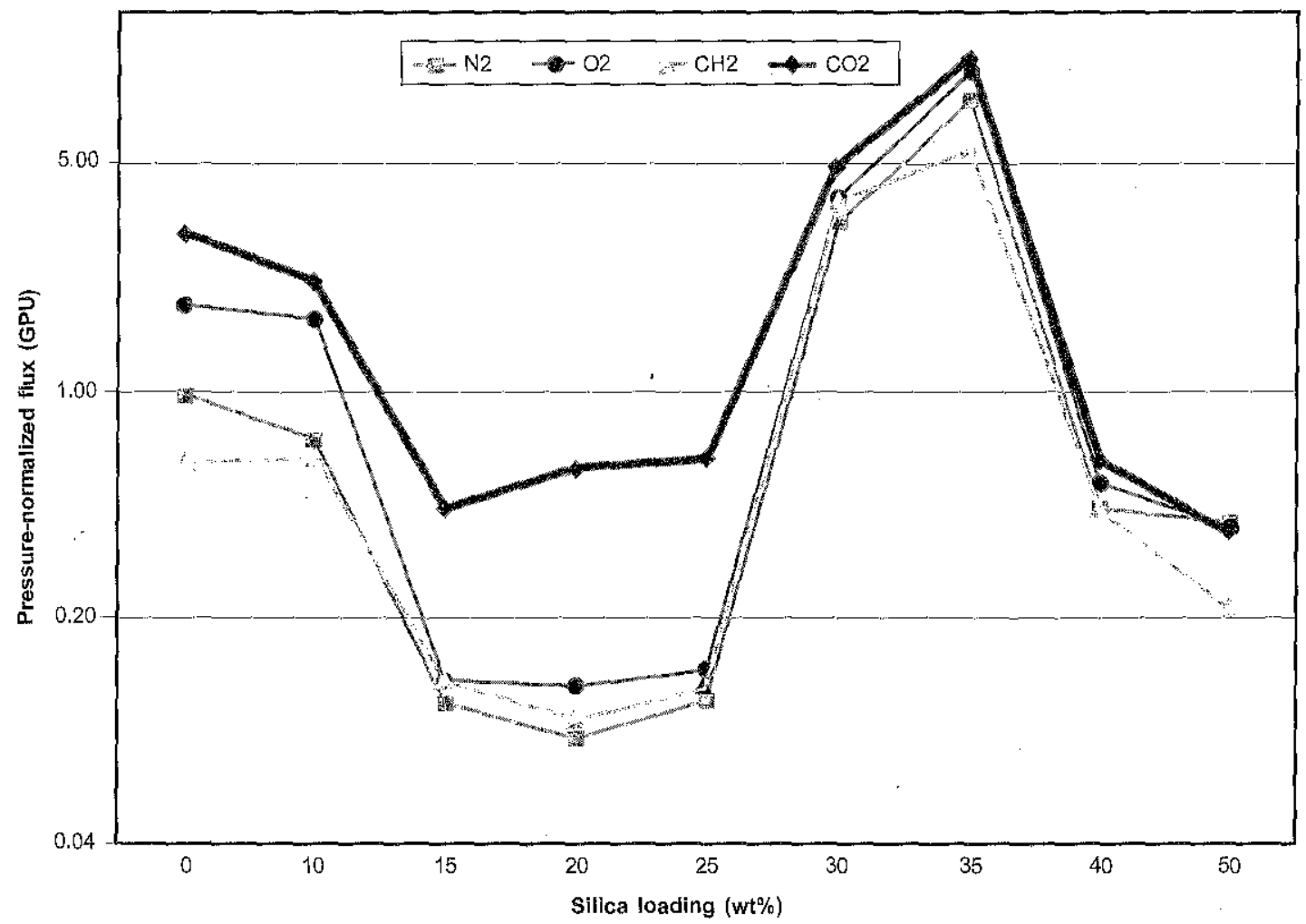

Figure 8 The permeability of $\mathrm{CO}_{2}, \mathrm{O}_{2}, \mathrm{~N}_{2}$ and $\mathrm{CH}_{4}$ gases at 4 bar pressure with membrane of different silica loading

loadings. As can be seen, for pure polyimide $\left(\mathrm{M}_{0}\right)$ the permeability of test gases varies in the order of: $\mathrm{CO}_{2}>\mathrm{O}_{2}>\mathrm{N}_{2}>\mathrm{CH}_{4}$ due to molecular size variations of the gases. Based on the well-known solution-diffusion mechanism, the permeability of gases through nonporous polymer membranes is defined as a combination of diffusion and solution processes. The differences in the gas permeabilities measured for pure polyimide is due to molecular size variations of the gases. Generally speaking, the smaller size molecules can diffuse faster and as a result, have higher permeabilities [21]. In glassy polymer such as polyimide, the mobility term is usually dominant, permeability falls with increasing permeate size, and small molecules permeate preferentially [22]. In pure polyimide $\left(\mathrm{M}_{0}\right)$, the polymer chains are essentially fixed and do not rotate [22] and by adding silica fillers to the polyimide matrix will restrain the diffusion of the gases through the membrane matrix due to increasing the tortuosity of the matrix [23]. This resulted in the decreased of $\mathrm{CO}_{2}, \mathrm{~N}_{2}, \mathrm{O}_{2}$ and $\mathrm{CH}_{4}$ gases permeability at 10 to $25 \mathrm{wt} \%$ of silica loading. The lowest permeability shows in $\mathrm{M}_{15}, \mathrm{M}_{20}$ and $M_{25}$ membrane where better bonding between silica and polyimide matrix ware displayed and significant reduction in gas solubilities occur because the alkoxides formed separate, inaccessible, organo-silicate structures with little cross-linking and interpenetration into the polyimide matrix, decreasing the total amount of free volume available for dissolution of gas [24]. The presence of interconnection of silica particles to polyimide also brings about some sort of physical barriers in the hybrid membrane which changes the gas permeation pathway to an indirect path, hence resulting in decreased polymer permeability [7].

Figure 8 also shows that incorporation of silica particles results in an increase of $\mathrm{CH}_{4}$ permeability higher than the $\mathrm{N}_{2}$ permeability at 15 to $30 \mathrm{wt} \%$ of silica loading. The addition inorganic particles into 
polyimide, disrupts polymer chain packing [25] and demonstrates the gas transport in these membranes were combined with the Knudsen diffusion mechanism through the pores. The gas separation via Knudsen diffusion mechanism favors lower molecular weight penetrant; therefore more $\mathrm{CH}_{4}$ was allowed to permeate through the membrane compared to $\mathrm{N}_{2}$ [26]. As could be inferred from Figure 8 , incorporation of silica particles at 15 to $30 \mathrm{wt} \%$ loading, results in a further increase in the permeability of $\mathrm{CH}_{4}$ higher than the $\mathrm{N}_{2}$ permeability. Nevertheless, the solution diffusion mechanism work to maintain the high permeability for $\mathrm{O}_{2}$ and $\mathrm{CO}_{2}$ gases due to small permeate size and even more for $\mathrm{CO}_{2}$ gas for its superior condensability.

As the silica loading increasing to 30 and 35 $w t \%$, permeability of test gases becomes even higher than the permeability of intrinsic polymer $M_{0}$ membrane. These indicate the dominance of Knudsen diffusion mechanism. The $\mathrm{M}_{30}$ and $\mathrm{M}_{35}$ membranes morphological changes occurs at the interface between the silica and the polyimide matrix, resulting in the increased of free volume of the membrane matrix and existence of pinholes/voids on the surface of the hybrid membranes samples, as confirmed by SEM images (Figure 7(b)). These hybrid membrane samples demonstrated insufficient adhesion between the phases causing Knudsen diffusion mechanism took place in microporous silica inorganic filler and through pinholes in the hybrid membrane samples [27].

In contrast, $\mathrm{M}_{40}$ and $\mathrm{M}_{50}$ membranes show lower permeability than they were in $\mathrm{M}_{30}$ and $\mathrm{M}_{35}$ membranes. The lost of silica in the membranes causing them to act as a pure polyimide membrane. But, with small amount of silica particles left bonded to the polyimide matrix, it promote slower permeation of the test gases and silica act to further reduce the amount of free volume available for gas penetration by disrupting the polymer chain of the hybrid materials in the membranes.

\subsection{The Selectivity Study of Polyimide- silica Membrane}

The selectivity results are shown in Figure 9. Despite the good bonding of silica and polyimide matrix in the hybrid membrane, the selectivity of $\mathrm{O}_{2} / \mathrm{N}_{2}$ and $\mathrm{N}_{2} / \mathrm{CH}_{4}$ gases cannot suppress the selectivity of pure polyimide membrane except for $\mathrm{M}_{10}$ membrane with the value of 2.36 for $\mathrm{O}_{2} / \mathrm{N}_{2}$ separation which is more than pure polyimide $\left(\mathrm{M}_{0}\right)$ selectivity at 1.88. As well as for $\mathrm{M}_{50}$ membrane that has higher selectivity for $\mathrm{N}_{2} / \mathrm{CH}_{4}$ gases selectivity with the value of 1.81 that higher than 1.61 selectivity values at $M_{0}$ membrane. Even if these two hybrid membranes $\left(\mathrm{M}_{10}\right.$ and $\mathrm{M}_{50}$ membranes) have shown higher selectivity for $\mathrm{O}_{2} / \mathrm{N}_{2}$ and $\mathrm{N}_{2} / \mathrm{CH}_{4}$, the values are still not that far from the pure polyimide separation performance. The selectivity values for $\mathrm{O}_{2} / \mathrm{N}_{2}$ and $\mathrm{N}_{2} / \mathrm{CH}_{4}$ gases did not show any significant trend with the silica loading since the $\mathrm{N}_{2}$ and $\mathrm{O}_{2}$ are non-condensable and non-polar gases [21]. The solubility of the gases does not change with the variety of silica content.

The lowest selectivity for all test gases was shown in $\mathrm{M}_{30}$ and $\mathrm{M}_{35}$ membranes where the silica content was most incompatible. The weak interaction between the silica and polymer leads to the formation of some voids at the interface of the two phases (polymer and silica) [28] which in turn results in dominance of undesirable Knudsen diffusion mechanism that do not help in separation performance in gas transport for small size permeates.

On the other hand, the selectivity of $\mathrm{CO}_{2} \mathrm{~N}_{2}$ was much higher in the hybrid membrane at 20 wt \% and $25 \mathrm{wt} \%$ silica loading than in the pure polyimide membrane $\left(\mathrm{M}_{0}\right.$ membrane). The solubility dominance at $20 \mathrm{wt} \%$ and $25 \mathrm{wt} \%$ silica loading gives the advantages of high $\mathrm{CO}_{2} /$ $\mathrm{CH}_{4}$ selectivity. The $\mathrm{CO}_{2} / \mathrm{CH}_{4}$ separation properties for $\mathrm{M}_{25}$ and $\mathrm{M}_{20}$ membranes demonstrate an increase in selectivity from 5.03 to 5.10 and an increased from 5.03 to 5.99 , respectively. This can be explained by the increasing of solubility for $\mathrm{CH}_{4}$ as condensable gas as the silica particles in polyimide membrane were well-bonded and the quantity was compatible for the incorporation.

The good union between silica particles and polyimide matrix at $20 \mathrm{wt} \%$ and $25 \mathrm{wt} \%$ silica loading also demonstrate an increased in $\mathrm{CO}_{2} \mathrm{~N}_{2}$ selectivity value. At $\mathrm{M}_{25}$ membrane $\mathrm{CO}_{2} / \mathrm{N}_{2}$ selectivity value increased from $3.12\left(\mathrm{M}_{0}\right.$ 


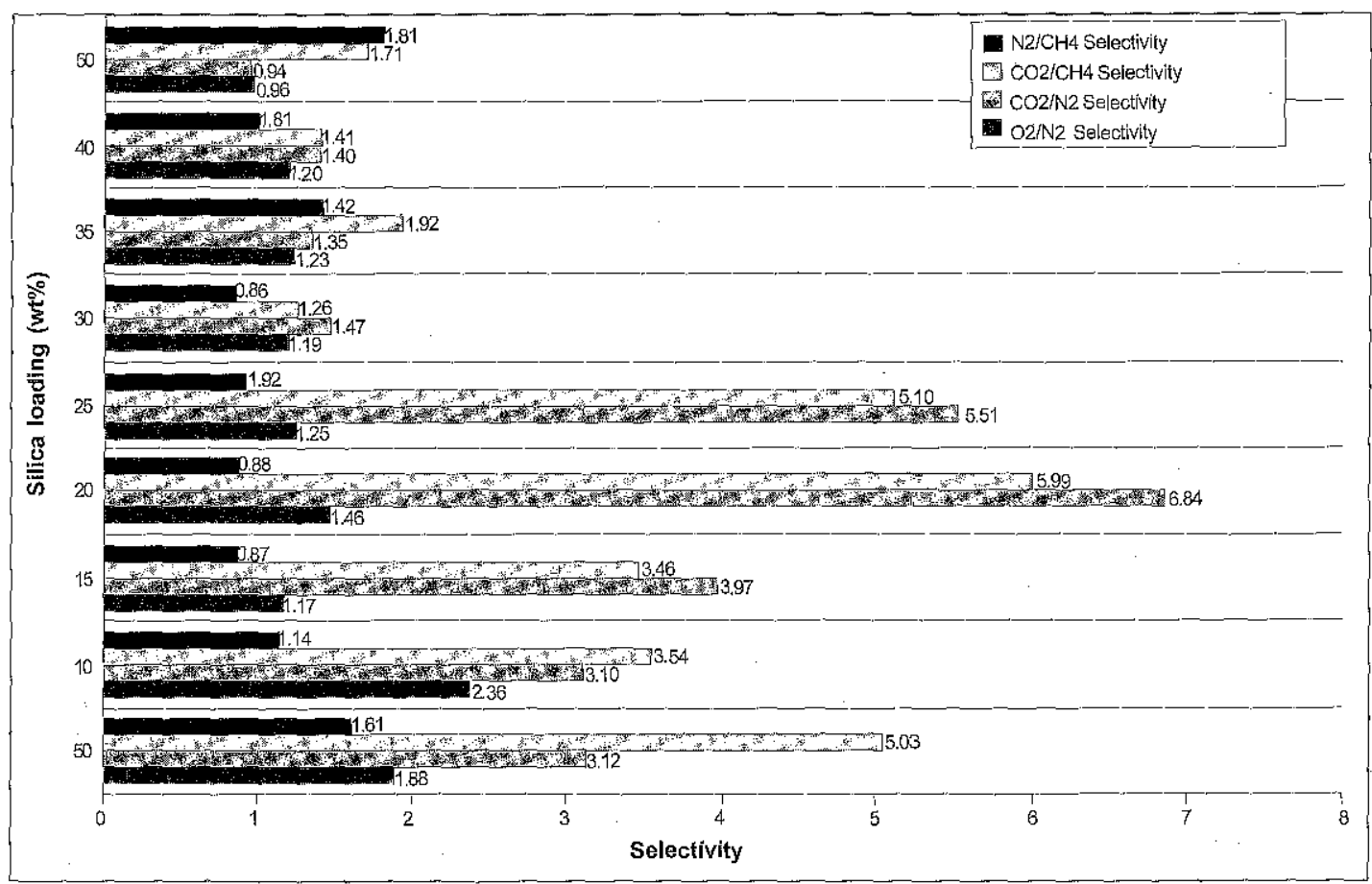

Figure 9 Selectivity of polyimide-silica hybrid membrane for $\mathrm{O}_{2} / \mathrm{N}_{2}, \mathrm{CO}_{2} / \mathrm{N}_{2}, \mathrm{CO}_{2} / \mathrm{CH}_{4}$ and $\mathrm{N}_{2} / \mathrm{CH}_{4}$. gas pairs

membrane) to 5.50 . While at $\mathrm{M}_{20}$ membrane $\mathrm{CO}_{2} / \mathrm{N}_{2}$ selectivity value increased from 3.12 $\left(\mathrm{M}_{0}\right.$ membrane) to 6.84 , about two time higher than the pure polyimide $\mathrm{CO}_{2} \mathrm{~N}_{2}$ selectivity value. The increasing selectivity attributed to the superior solubility selectivity of polar $\mathrm{CO}_{2}$ gas and solubility selectivity which favors $\mathrm{CO}_{2}$ gas as the most condensable gas molecule. Overall, the $20 \mathrm{wt} \%$ and $25 \mathrm{wt} \%$ of silica loading was the optimum value to create the good interaction between silica and polyimide matrix and increased the gas separation performance.

\subsection{CONCLUSION}

In this study, the hybrid membranes were fabricated with organic-inorganic materials from polyimide and silica. The microporous silica was produced through sol-gel process where TEOS was used as an alkoxide precursor. The polyimide and polyimide-silica hybrid membranes were fabricated at different silica loading of $0-50 \mathrm{wt} \%$.
The effects of silica loading on the polyimide membrane were investigated. Based on the experimental results hybrid organic-inorganic membranes demonstrated that polyimide polymer matrix and silica sol particles have been successfully fabricated using the sol-gel method. FTIR spectroscopy successfully uncovered the signature peaks that are characteristic of silica sol structures in the membrane regions. More specifically, signs of $\mathrm{Si}-\mathrm{O}$-Si molecular substructures were found in the entire hybrid membrane samples, as well as $\mathrm{Si}$ $\mathrm{OH}$ was present at hybrid membranes with $20 \mathrm{wt} \%$ to $40 \mathrm{wt} \%$ of silica loading. SEM results verified the presence and the dispersion of silica particles in polymer matrix that differ according to the silica loading. The difference in morphology and silica loading of hybrid membrane samples set a trend in gas separation properties that indicate a decrease in permeability for high selectivity membrane and an increase in permeability when the selectivity is low. The trend applies well with the Robeson's Upper Bound for gas separation properties. The gas separation performance was influenced by the 
compatibility of silica amount to interact with polyimide matrix. The sol-gel reaction itself is sensitive to different variables, so the silica sol loading should be at the optimum value to create the interaction between silica and polyimide matrix. The optimum amount of silica at 20 to $25 \mathrm{wt} \%$ loading for hybrid membranes increased the separation $\mathrm{CO}_{2} \mathrm{~N}_{2}$ and $\mathrm{CO}_{2} / \mathrm{CH}_{4}$ gases higher than the intrinsic polymer.

\section{ACKNOWLEDGMENT}

The authors gratefully acknowledged the Research Management Center, Universiti Teknologi Malaysia, for supporting this research through Research University Grant, Vot. No. Q.J130000.2509.01H64

\section{REFERENCES}

[1] T. Kono, Y. Hu, T. Masuda, Ka. Tanaka, R. D, Priestley, B. D. Freeman. 2007. Effect of Fumed silica Nanoparticles on the Gas Permeation Properties of Substituted Polyacetylene Membrane. Polym. Bull. 58: 995.

[2] H. Cong, M. Radosz, B. F. Towler, Y, Shen. 2007. Polymer-inorganic Nancomposites Membranes for Gas Separation. Sep. Purif. Techno. 55: 281.

[3] Q. Zhang, K. Naito, Y. Kagawa.2007. Synthesis and Mechanical Properties of Advanced Polyimide/Silicon Dioxide Nanocomposites. Mater, Sci. Forum. 561565: 709 .

[4] T. T. Moore, W. J. Koros. 2005. Non-ideal Effects in Organic-inorganic Materials for Gas Separation Membranes. J. Membr. Sci. 739: 87.

[5] W. A. W. Rafizah, A. F. Ismail, 2008. Effect of Carbon Molecular Sieve Sizing with Poly(vinyl pyrrolidone) K-15 on Carbon Molecular Sieve-polysulfone Mixed Matrix Membrane. J. Membr. Sci. 307: 53.

[6] T. D. Kusworo, A. F. Ismail, A. Mustafa, T. Matsuura. 2008. Dependence of Membrane Morphology and Performance on
Preparation Conditions: The Shear Rate Effect in Membrane Casting. Sep. Purif. Techno. 61: 249.

[7] J. H. Kim, Y. M. Lee. 2001. Gas Permeation Properties of Poly (amide-6-b-ethylene oxide)-silica Hybrid Membranes. J. Membr. Sci. 193: 209.

[8] X. Liu, Y. Peng, S. Ji. 2008. A New Method to Prepare Organic-inorganic Hybrid Membranes. Desalination. 221: 376.

[9] L. Shao, T. Chung, S. H. Goh, K. P. Pramoda. 2004. Transport Properties of Cross linked Polyimide Membranes Induced by Fifferent Generations of Diaminobutane (DAB) Dendrimers. J. Membr. Sci. 238: 153.

[10] C. Hibshman, C.J. Cornelius, E. Marand, 2003. The Gas Separation Effects of Annealing Polyimide-organosilicate Hybrid Membranes. J. Membr. Sci. 211: 25.

[11] M. Moaddeb, W. J. Koros. 1997. Gas Transport Properties of Thin Polymeric Membranes in the Presence of Silicon Dioxide Particles. J. Membr. Sci. 125: 143.

[12] C. Joly, S. Goizet, J. C. Schrotter, J. Sanchez, M. Escoubes. 1997. Sol-gel Polyimide-silica Composite Membrane: Gas Transport Properties. J. Membr. Sci. 130: 63.

[13] C. Cornelius, C. Hibshman, E. Marand. 2001. Hybrid Organic-inorganic Membranes. Sep. Purif, Techno. 25: 181.

[14] A. F. Ismail, T. D. Kusworo, A. Mustafa. 2008. Enhanced Gas Permeation Performance of Polyethersulfone Mixed Matrix Hollow Fiber Membranes using Novel Dynasylan Ameo Silane Agent. $J$. Membr. Sci. 31: 306.

[15] K. C. Khulbe, C. Feng, T. Matsuura, M. Khayet. 2006. Polymeric Hollow Fibers: State of the Art Review of Their Preparation, Characterization and Applications in Different Research Areas. J. Appl. Membr. Sci. Techno. 4: 53.

[16] S. Zhong, C. Li, X. Xiao. 2002. Preparation and Characterization of Polyimide-silica Hybrid Membranes on Kieselguhr-mullite Supports. J. Membr. Sci. 199: 53.

[17] M. Munoz-Aguado, M. Gregorkiewitz. 1997. Sol-gel Synthesis of Microporous 
Amorphous Silica from Purely Inorganic Precursors. J. Colloid Interf. Sci. 185: 459.

[18] E. Suzuki. 2002. High-resolution Scanning Electron Microscopy of Immunogoldlabelled Cells by the Use of Thin Plasma Coating of Osmium. J. Microsc. 208 (3): 153.

[19] C. J. Brinker, G.W. Scherer. 1990. Sol-Gel Science - The Physics and Chemistry of Sol-Gel Processing. San Diego: Academic Press inc.

[20] T. T. Moore, W. J. Koros. 2005. Non-ideal Effects in Organic-inorganic Materials for Gas Separation Membranes. J. Molecular Structure. 739: 87.

[21] M. Sadeghi, G. Khanbabaei, A. H. S. Dehaghani, Mohammad Sadeghi, M. A. Aravand, M. Akbarzade, S. Khatti. 2008. Gas Permeation Properties of Ethylene Vinyl Acetate-silica Nanocomposite Membranes. J. Membr. Sci. 322: 423.

[22] R. W. Baker. 2004. Membrane Technology and Application. $2^{\text {nd }}$ Edition. New York: McGraw-Hill.

[23] M. Sadeghi, M. A. Semsarzadeh, H. Moadel. 2009. Enhancement of the Gas Separation Properties of Polybenzimidazole (PBI)
Membrane by Incorporation of Silica Nano Particles. J. Membr. Sci. 331: 21.

[24] C. J. Cornelius, E. Marand. 2002. Hybrid Silica-polyimide Composite Membranes: Gas Transport Properties. J. Membr. Sci. 202: 97

[25] Z. He, I. Pinnau, A. Morisato. 2002. Nanostructured Poly(4-methyl-2-pentyne)/ Silica Hybrid Membranes for Gas Separation. Desalination. 146: 11.

[26] F. Aziz , A. F. Ismail. 2010. Preparation and Characterization of Cross-linked Matrimid ${ }^{\circledR}$ Membranes using Paraphenylenediamine for $\mathrm{O}_{2} / \mathrm{N}_{2}$ Separation. Sep. Purif. Techno. 73: 421.

[27] May-Britt Hägg. 2008. Membranes in Gas Separation. In Anil K. Pabby, S.H. Rizvi and Maria Sastre. Handbook of Membrane Separations: Chemical, Pharmaceutical, Food, and Biotechnological Applications. USA: CRC Press. 65-105.

[28] J. Ahn,W. J. Chung, I. Pinnau, M.D. Guiver. 2008. Polysulfone-silica Nanoparticle Mixed Matrix Membranes for Gas Separation. $J$. Membr. Sci. 314: 123. 